\title{
Powder Metallurgy Preparation of Co-Based Alloys for Biomedical Applications
}

\author{
I. MAReK ${ }^{a, *}$, P. Novák ${ }^{a}$, J. MlynáR ${ }^{a}$, D. VojtěCh ${ }^{a}$, T.F. Kubatík ${ }^{b}$ And J. MÁleK \\ ${ }^{a}$ Institute of Chemical Technology Prague, Department of Metals and Corrosion Engineering, \\ Technická 5, 16628 Prague 6, Czech Republic \\ ${ }^{b}$ Institute of Plasma Physics CAS, v.v.i., Za Slovankou 1782/3, 18200 Prague 8, Czech Republic
} ${ }^{c}$ UJP Praha a.s., Nad Kamínkou 1345, 15610 Praha-Zbraslav, Czech Republic

\begin{abstract}
Co-based alloys represent very important group of materials used for medical applications. Currently, fabrication of these materials is preferentially done by casting or forming. Production by powder metallurgy techniques is less common. However, powder metallurgy fabrication of these alloys brings advantages such as reduced machining, possibility of alloying by high-melting elements, preparation of nanocrystalline materials with enhanced mechanical properties or producing of porous alloys with improved ability to integrate into issues. In this work, our attention was focused on fundamental preparation of an CoCrMo alloy by two methods of powder metallurgy. In the first method, pure metallic powders were mixed, pressed and sintered in vacuum furnace. The second applied technology consisted of mechanical alloying using planetary ball mill and compaction by spark plasma sintering technique. A series of samples was prepared under various conditions by these procedures. Dependence of microstructure, phase composition and mechanical properties of prepared samples on fabrication conditions (milling parameters, sintering temperature etc.) was studied. Obtained results were compared with properties of commercial cast cobalt alloy used for medical applications.
\end{abstract}

DOI: 10.12693/APhysPolA.128.597

PACS: 62.20.Qp, 62.20.F-, 64.70.kd

\section{Introduction}

Nowadays, high demands are placed upon the materials used for load bearing parts of orthopaedic implants. Three main reasons for the selection of biomaterials are mechanical properties (the Young modulus, fatigue strength and fracture resistance, wear resistance and coefficient of friction), chemical properties (corrosion resistance) and biocompatibility with biological tissue $[1,2]$. Major metallic materials used in medical applications today include titanium and its alloys (largely $\alpha+\beta$ alloys: $\mathrm{Ti}-6 \mathrm{Al}-4 \mathrm{~V}, \mathrm{Ti}-6 \mathrm{Al}-7 \mathrm{Nb}$ alloy, and several $\beta$-Ti alloys), stainless steel, and cobalt-based alloys (primarily $\mathrm{Co}-28 \mathrm{Cr}-6 \mathrm{Mo}$ alloy). Titanium and its alloys are widely exploited as implants in orthopaedics, dentistry and cardiology due to high strength and excellent biocompatibility [3]. However, these materials are seldom used in tribological situation, mainly because of their poor wear resistance. The austenitic stainless steel is recommended rather for short-term implants with regard to danger of allergic reaction appearance in a big number of patients [1]. The first medical use of cobalt-based alloys was in the production of dental implants due to their excellent resistance to degradation in the oral environment. Results of various in vitro and in vivo tests have shown that the alloys are biocompatible and suitable for use as surgical implants.

Today, the main use of cobalt-based alloys is related to orthopaedic prostheses for the femoral or shoulder

${ }^{*}$ corresponding author; e-mail: ivo.marek@vscht.cz components as well as to fracture fixation devices $[1,4]$. At room temperature, pure cobalt has a hexagonal closepacked crystallographic structure (hcp). At the temperature of $422^{\circ} \mathrm{C}$, this structure undergoes the allotropic transformation to a face-centered cubic (fcc) structure [5]. Strengthening of cobalt alloys is obtained through a combination of solid-solution hardening and carbide precipitation hardening by the addition of carbon, chromium and molybdenum [6]. Chromium and molybdenum enhance the corrosion resistance of alloys and also stabilize the hcp-structure of cobalt matrix, which has been considered important to improve the mechanical properties, to reduce the abrasive wear and to lower the stacking faults energy. Unfortunately, presence of stacking faults considerably decreases ductility of $\mathrm{Co}^{-}$ $\mathrm{Cr}-\mathrm{Mo}$ alloys [7].

Effect of carbon addition to cobalt-based alloys has been described in the cast and forged materials. Content of carbon up to $0.1 \mathrm{wt} \%$ in forged materials does not affect resulting microstructure. Presence of carbides was not observed. Microstructure consists of equiaxed grains containing stacking faults, twins and $\varepsilon$-martensite phase. Increasing carbon content (above 0.1 wt\%) reduces amount of these defects and components and supports formation of chromium carbide $\mathrm{Cr}_{23} \mathrm{C}_{6}[8,9]$.

Investigation of cast cobalt alloys with higher carbon content showed that microstructure was composed of dendrites of solid solution and interdendritic carbides. These carbides are of two morphologies - "lamellar" which is thought to be the most detrimental morphology to the mechanical properties of as-cast components and "blocky" carbides that are more desirable [10]. 
Mechanical properties of cobalt-based alloys do not depend only on the chemical composition but also on the fabrication process. Casting process provides desirable processing flexibility and lower initial costs. However, distinct limitations are associated with casting, such as coarse grains, non-uniform microstructure and lower tensile and fatigue strength. These drawbacks can be overcome by using wrought alloys [10].

In recent years cobalt-based materials with improved properties have been fabricated by means of powder metallurgy. When compared with conventionally produced (cast/wrought) alloy, samples made by the powder metallurgy process were found capable of higher tensile and fatigue strength, increased hardness, finer grain size and more uniform structure that is less prone to segregation. The powder metallurgy processed alloy also provides the same relative benefits even after exposure to the elevated temperatures typically associated with annealing or forging of orthopaedic implants [11].

The crucial process in mechanical milling or alloying is the ball-powder-ball collision. Powder particles are trapped between the colliding balls during milling and undergo deformation and/or fracture processes which define the structure of the powder. The energy of the milling depends on the type of the mill, the power supplied to drive the milling chamber and composition, size, and size distribution of the balls. One important process variable is the temperature inside of the milling vessel and that induced in the powders by the kinetic energy of the milling balls. This temperature may be critical for the reactions or transformations in the powders during milling [12].

\section{Experiment}

The aim of this work was to prepare a cobalt-based alloy with composition $\mathrm{Co}-28 \mathrm{Cr}-6 \mathrm{Mo}-0.25 \mathrm{C}$ by two powder metallurgy technologies.

The first process included cold pressing and subsequent sintering. Appropriate amounts of powder metals of defined purity and particle size (Co - MERCK, 99.9\%, $1 \mu \mathrm{m}$; Cr — Sigma Aldrich, 99.5\%, $44 \mu \mathrm{m}$; Mo Penta, 99.9\%, $44 \mu \mathrm{m}$ ) and carbon (graphite, $10 \mu \mathrm{m}$ ) were mixed and subsequently pressed by the pressure of $630 \mathrm{MPa}$ into green bodies with diameter of $10 \mathrm{~mm}$ using universal testing machine LabTest 5.250SP1-VM. The prepared pellets were sintered in vacuum induction furnace at the temperatures of $1250^{\circ} \mathrm{C}$ and $1350^{\circ} \mathrm{C}$ for 4, 8, and $12 \mathrm{~h}$. Sintering was performed in UJP Praha Company.

Second technology included mechanical alloying and consolidation by spark plasma sintering (SPS). The mixture of pure metal and carbon powders was milled in the planetary ball mill Retsch PM 100 CM under the argon protective atmosphere at room temperature. The milling vessel and the balls were made of stainless steel. Powder to ball weight ratio was approximately 1:70. Optimal milling conditions were found by varying the milling time $(30,60,120$, and $180 \mathrm{~min})$ and the rotation speed
$(100,200,400,600 \mathrm{rpm})$. Influence of the milling time and the rotation speed on phase composition of the prepared powder was investigated using X-ray diffraction analysis (XRD) (PANalytical X 'Pert Pro). Microstructure was studied by means of scanning electron microscope (SEM) (TESCAN VEGA 3 LMU). Consolidation of the powders prepared by the mechanical alloying was performed at the Institute of Plasma Physics CAS, v.v.i. by using SPS apparatus (Thermal Technology SPS 10-4). The powder in a graphite die was heated to $1000^{\circ} \mathrm{C}$ at a heating rate of $200^{\circ} \mathrm{C} / \mathrm{min}$ with a pressure of $80 \mathrm{MPa}$. The holding time was $10 \mathrm{~min}$. Samples obtained from cast knee prosthesis were used as a reference material.

Grinding papers ( $\mathrm{P}$ 80-P 4000) and polishing diamond paste (D2, particle size $2-3 \mu \mathrm{m}$ ) were used for preparation of metallographic samples. Microstructure was revealed by etching in aqua regia for $5 \mathrm{~s}$. Microstructure was studied by means of light microscopy (LM) using metallographic microscope Olympus PME 3 and image analyzer Lucia 4.8. Phase composition was determined by XRD phase analysis.

For compressive tests, samples were cut and grinded into the shape of a cube with an edge length of $5 \mathrm{~mm}$. These tests were carried out using universal testing machine LabTest 5.250SP-1 VM. Vickers hardness tests with the load of $30 \mathrm{~kg}$ were also performed.

\section{Results and discussion}

In the microstructure of cast knee implant dendrites of solid solution and "blocky" carbides situated in interdendritic spaces were visible (Fig. 1). By XRD phase analysis it was found that matrix was composed of cobalt solid solution with both crystallographic modifications (fcc, hcp) and $\mathrm{Cr}_{23} \mathrm{C}_{6}$ chromium carbide. Presence of both cobalt crystallographic modifications is probably due to the content of alloying elements which influence the transformation temperature, and also due to cooling rate after casting [13]. Vickers hardness of this sample

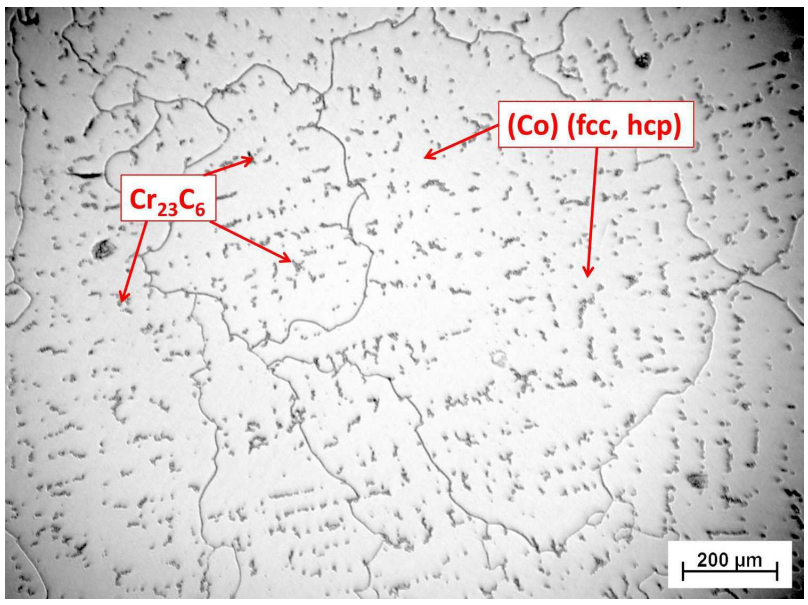

Fig. 1. Microstructure of cast knee implant. 


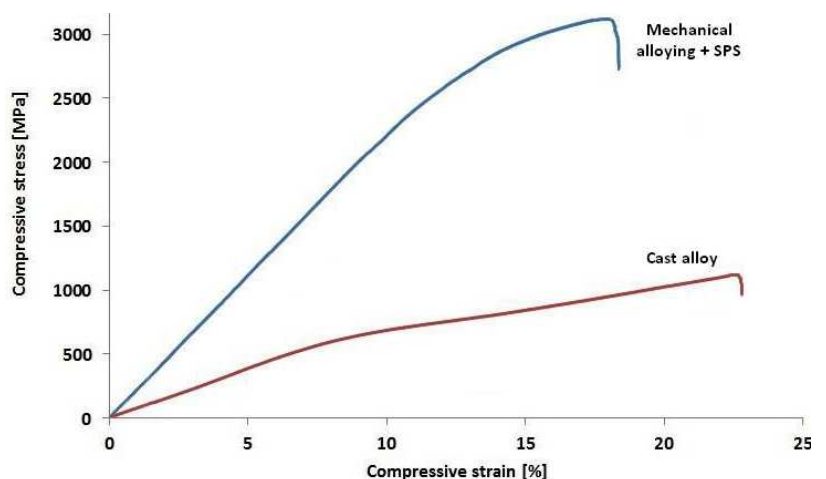

Fig. 2. Compressive curves of Co-based alloys prepared by different technologies.

reached $298 \pm 4 \mathrm{HV} 30$. By mechanical tests, compressive yield strength of $550 \mathrm{MPa}$ and compressive ultimate strength of $1060 \mathrm{MPa}$ were determined (see Fig. 2). These values are in a good agreement with data available for the commercial alloy [14].

Influence of sintering conditions on microstructure and phase composition was studied at two temperatures $\left(1250\right.$ and $\left.1350{ }^{\circ} \mathrm{C}\right)$ and three sintering durations $(4,8$, and $12 \mathrm{~h}$ ). By XRD phase analysis it was found that at $1250^{\circ} \mathrm{C}$ no carbides were formed irrespective of sintering time and only cobalt solid solution with hexagonal structure was detected (Fig. 3).

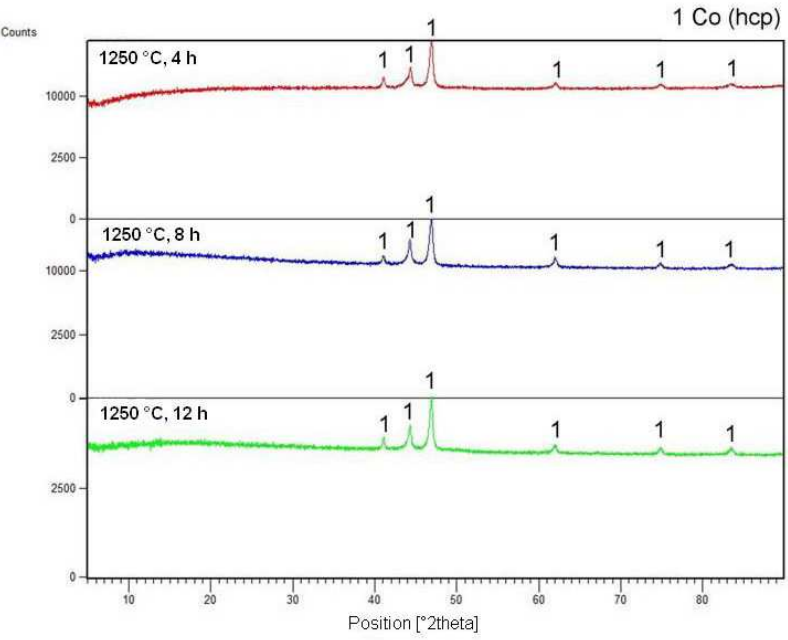

Fig. 3. Phase composition of the samples sintered at $1250{ }^{\circ} \mathrm{C}$.

Although result of XRD phase analysis did not confirmed presence of carbides, they are visible in the microstructure as small globular particles dispersed in the solid solution (Fig. 4). This difference in obtained results is probably caused by XRD detection limit (approximately 5\%).

On the other hand, samples sintered at $1350{ }^{\circ} \mathrm{C}$ were composed of hexagonal cobalt solid solution and chromium carbide $\mathrm{Cr}_{23} \mathrm{C}_{6}$ (Fig. 5). Intensity of diffraction lines revealing presence of chromium carbide decreased

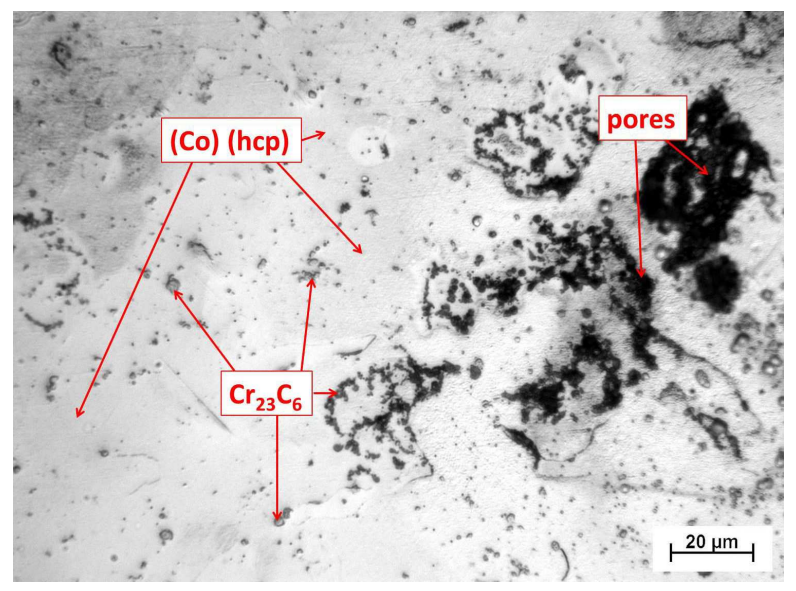

Fig. 4. Microstructure of the sample sintered at $1250{ }^{\circ} \mathrm{C}$ for $4 \mathrm{~h}$.

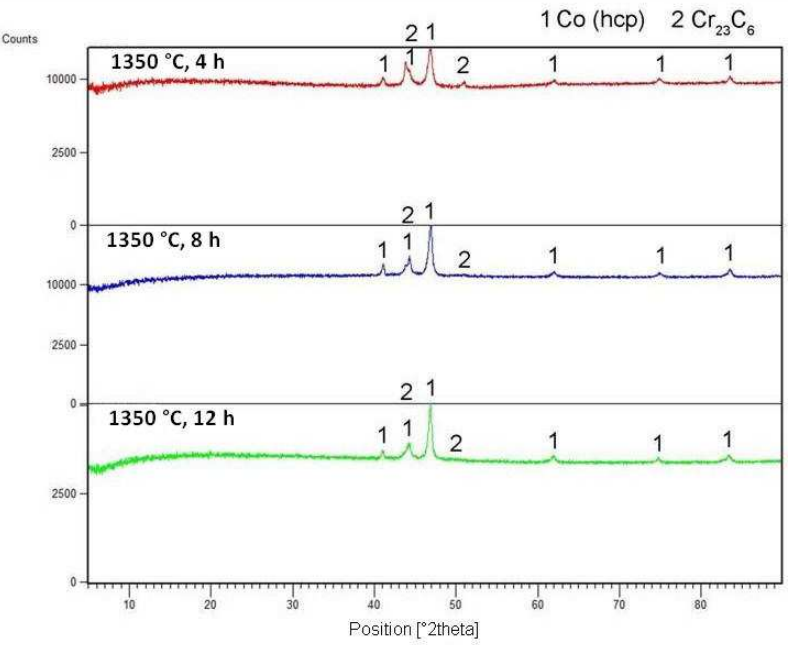

Fig. 5. Phase composition of the samples sintered at $1350{ }^{\circ} \mathrm{C}$.

with increasing time of sintering which is most likely the consequence of decreasing carbide content. It was also confirmed by microstructure investigation.

For illustration, in Fig. 6 there is shown microstructure of sample sintered for $4 \mathrm{~h}$ with highest carbide content. Chromium and molybdenum stabilize hexagonal structure of cobalt solid solution and this finding was confirmed by XRD in all sintered samples. Light micrographs were also used for porosity assessment. It was found that porosity decreases with increasing sintering time and temperature most likely due to better diffusion between powder components. Vickers hardness of samples sintered at $1250^{\circ} \mathrm{C}$ and $1350^{\circ} \mathrm{C}$ slightly increased with sintering time from $120 \pm 5$ to $130 \pm 5 \mathrm{HV} 30$ and from $150 \pm 8$ to $170 \pm 9 \mathrm{HV} 30$, respectively. Nevertheless, these values are significantly lower than the hardness of the cast alloy. This can be attributed to higher porosity of sintered samples. Compressive tests could not be performed representatively considering the dimensions and geometry of the samples. 


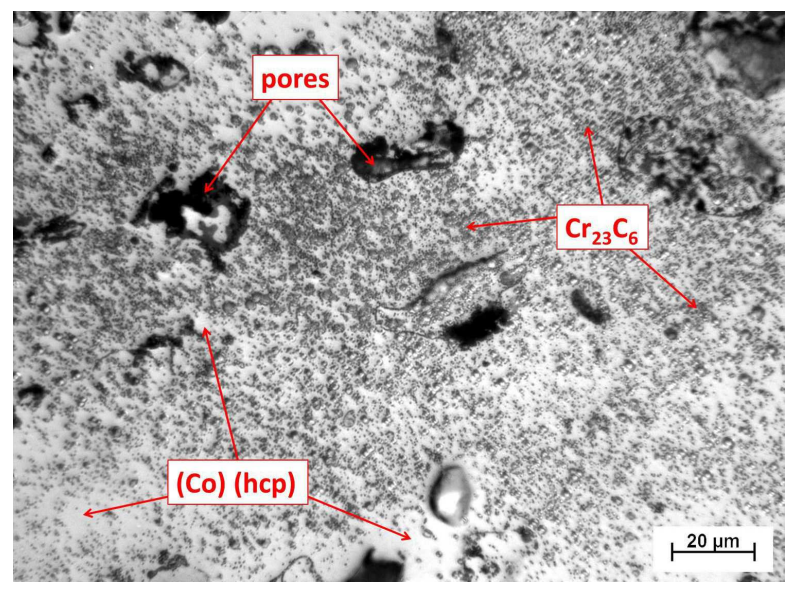

Fig. 6. Microstructure of the sample sintered at $1350{ }^{\circ} \mathrm{C}$ for $4 \mathrm{~h}$.

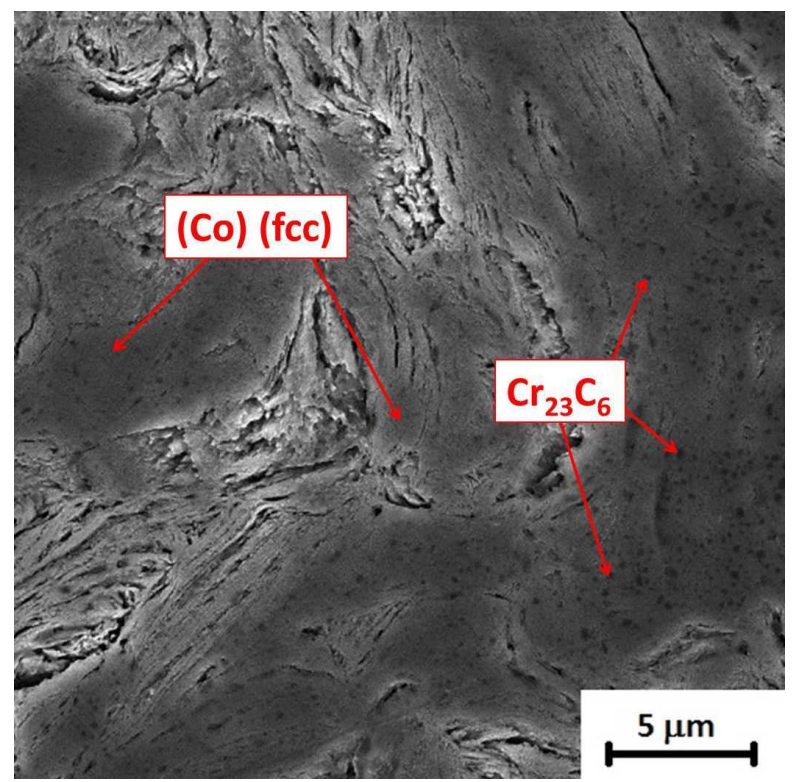

Fig. 7. SEM micrograph of mechanically alloyed powder (400 rpm, $2 \mathrm{~h})$.

Optimal conditions for preparing powders by mechanical alloying were found $400 \mathrm{rpm}$ and $2 \mathrm{~h}$. These conditions were adjusted on the basis of results from XRD phase analysis revealing presence of only solid solution of alloying elements in cobalt, and chromium carbide. Lower milling speed and shorter milling times did not lead to desired phase composition of the powder and residual amounts of undissolved chromium and molybdenum were still observed. SEM micrograph showing the microstructure of the powder is depicted in Fig. 7. There is visible morphology typical for mechanically alloyed materials where the dark stripes are pores between powder particles. In this case, the powder consisted of cobalt solid solution and dispersed fine chromium carbide particles. This powder was used as an initial material for spark plasma sintering.
XRD phase analysis of the compact sample revealed phase transformation of solid solution from fcc to hcp structure and presence of chromium carbide $\mathrm{Cr}_{23} \mathrm{C}_{6}$ (Fig. 8).

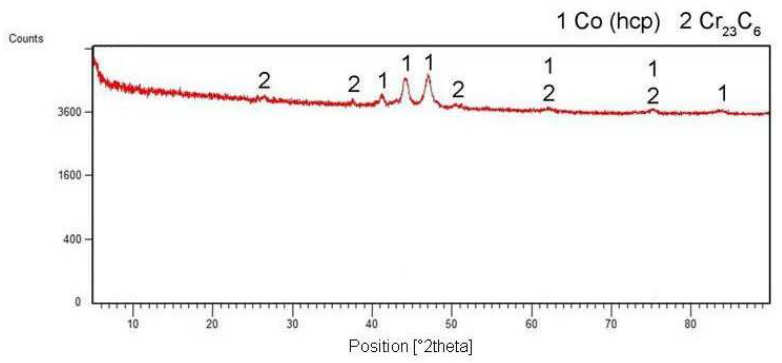

Fig. 8. Phase composition of the sample prepared by mechanical alloying and SPS.

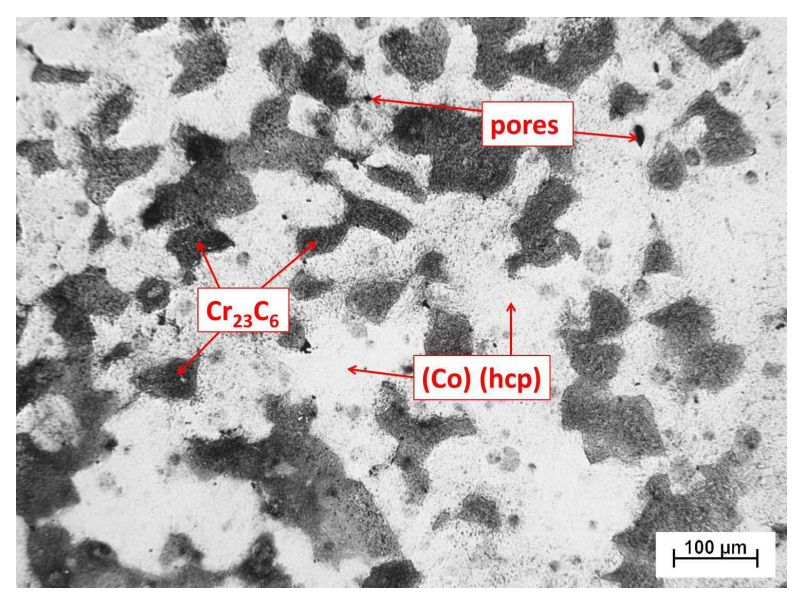

Fig. 9. Microstructure of compact sample processed by SPS.

Results of light microscopy showed that fine chromium carbides formed irregularly shaped clusters (Fig. 9). The porosity of this sample was considerably lower compared to pressed and sintered samples and reached only 0.1 vol.\%. Vickers hardness was of about $650 \pm 4 \mathrm{HV} 30$. With regard to mechanical properties it was found that the compressive yield strength reached almost $2200 \mathrm{MPa}$ and compressive ultimate strength more than $3100 \mathrm{MPa}$. These values strongly overcome the mechanical properties of cast cobalt alloy. This can be attributed to reducing of the grain size taking place during mechanical alloying and very low porosity. Comparison of compressive curves is shown in Fig. 2.

\section{Conclusion}

This work was focused on preparation of Co-based alloys for medical applications by powder metallurgy. It was found that simple cold pressing and subsequent sintering did not lead to desired phase composition and therefore the prepared alloys show too high porosity 
which is responsible for significant lowering of functional properties. Better results were obtained by using the combination of mechanical alloying and spark plasma sintering. $\mathrm{Co}-28 \mathrm{Cr}-6 \mathrm{Mo}-0.25 \mathrm{C}$ alloy showed superior mechanical properties when compared to conventional cast counterpart.

\section{Acknowledgments}

This project is financially supported by the Czech Science Foundation (project No. P108/12/G043).

\section{References}

[1] M. Grądzka-Dahlke, J.R. Dąbrowski, B. Dąbrowski, J. Mater. Process. Tech. 204, 199 (2008).

[2] Z. Oksiuta, J.R. Dabrowski, A. Olszyna, J. Mater. Process. Tech. 209, 978 (2009).

[3] Y.-H. Jeong, E.-J. Kim, W.A. Brantley, H.-C. Choe, Vacuum 107, 297 (2014).

[4] A. Marti, Injury 31, Suppl. 4 D18 (2000).

[5] A.H. Barry, G. Dirras, F. Schoenstein, F. Tétard, N. Jouini, Mater. Charact. 91, 26 (2014).
[6] T. Matković, P. Matković, J. Malina, J. Alloy Comp. 366, 1 (2004)

[7] L. Shi, D.O. Northwood, Z. Cao, J. Mater. Sci. 29 , 1233 (1994).

[8] C. Valero-Vidal, L. Casabán-Julián, I. HerriazCardona, A. Igual-Muñoz, Mater. Sci. Eng. C 33, 8 (2013).

[9] P. Hu, R. Liu, G. McRae, M.X. Yao, R. Collier, Mater. Des. 60, 424 (2014).

[10] R. Kaiser, K. Williamson, C. O'Brien, S. RamirezGarcia, D.J. Browne, J. Mech. Behav. Biomed. 24, 53 (2013).

[11] M. Walter, Benefits of PM Processed Cobalt-Based Alloy for Orthopaedic Medical Implants, Carpenter Technology Corp., Wyomissing, PA, USA 2006.

[12] C.C. Koch, in: Processing of Metals and Alloys, Eds. R.W. Cahn, P. Hassen, E.J. Kramer, Material Science and Technology, Vol. 15, A Comprehensive Treatment, VCH, Weinheim 1991, p. 193.

[13] J.V. Giacchi, C.N. Morando, O. Fornaro, H.A. Palacio, Mater. Charact. 62, 53 (2011).

[14] http://www.arcam.com/wp-content/uploads/ Arcam-ASTM-F75-Cobalt-Chrome.pdf. 